\title{
THE INFLUENCE OF FENTANYL ON AN ALFATHESIN INFUSION TECHNIQUE
}

\author{
G.L. Dunn, P.J. Houlton, D.H. Morison, and R. Rajagopalan
}

\begin{abstract}
ALFATHESIN has been recently released in Canada for use as an intravenous anaesthetic agent. Although it has been found to be an effective intravenous induction agent, ${ }^{1-4}$ there is evidence that it does not possess significant analgesic properties. ${ }^{5,6}$

The present study compares the effect of a small dose of fentanyl on an alfathesin infusion technique with nitrous oxide supplement, as assessed by cardiorespiratory variables, clinical efficacy, recovery times, and patient acceptability.
\end{abstract}

\section{METHODS}

Patients. Fifty-three unpremedicated female patients (A.S.A. status 1), undergoing aspiration and curettage for therapeutic abortion, were studied. Consent was obtained from all patients, who were randomly assigned in a double blind manner to one of two anaesthetic techniques.

Group $A$. Anaesthesia was induced with fentanyl $1 \mu \mathrm{g} / \mathrm{kg}$ followed by alfathesin $75 \mu \mathrm{l} / \mathrm{kg}$ administered into an intravenous infusion over a 30 second period and was maintained with an alfathesin infusion of approximately $3 \mu \mathrm{l} / \mathrm{kg} / \mathrm{min}$. Seventy per cent nitrous oxide in oxygen was administered by face mask from a circle system with an absorber.

Group B. Patients were anaesthetized using a technique identical to Group A, except that normal saline was substituted for fentanyl.

All patients breathed spontaneously and the use of vagolytic agents was avoided. Additional increments of alfathesin $75 \mu$ l were administered if a patient moved in response to a surgical stimulus.

\section{MeAsurements}

Physiological variables were recorded, and the recovery times were assessed according to a pre-

G.L.Dunn, M.B.,B.S.,F.F.A.R.C.S.,F.R.C.P.(C) P.J. Houlton, M.B., B.S.; D.H. Morison, M.B., Ch.B., F.R.C.P.(C); R. Rajagopalan, M.D., F.R.C.P.(C). Department of Anaesthesia, McMaster University, 1200 Main Street West, Hamilton, Ontario, Canada, L8S 4J9.

Canad. Anaesth. Soc. J., vol. 25, no. 4, July 1978 viously reported protocol. ${ }^{7}$ These included sys tolic blood pressure, pulse rate, respiratory rate and tidal volume. Recovery assessment included the time to "open eyes", "orientation", "sit up", and a "subjective recovery time".

\section{Statistical ANalysis}

Continuous data were analysed using a twotailed Student $t$ test. Binomial indices were compared using a Chi-square analysis, applying Yates's correction. For the purpose of this study, a probability of $P<.05$ was accepted as being significant.

\section{RESULTS}

Table I shows that 24 patients received alfathesin and fentanyl, and 29 alfathesin alone. There was no significant difference in mean age, or weight, or anaesthetic times between the groups.

Table $I I$ shows that 33 per cent of patients in Group A (with fentanyl) and 52 per cent in Group B (without fentanyl) required supplementary doses of alfathesin. The mean total dose of alfathesin administered in Group A was $104 \mu \mathrm{l} / \mathrm{kg}$, and in Group B was $110 \mu \mathrm{l} / \mathrm{kg}$. These differences were not statistically significant.

Physiological variables (Figure 1) are shown for the first six minutes after induction of anaesthesia.

Pulse rate (Figure la). Group A patients showed a slight initial rise in pulse rate at one minute, which had returned to the pre-operative level by the third minute. Group B patients showed an immediate but more marked and sustained rise in pulse rate. This difference was significant at the second to fourth minute.

Systolic blood pressure (Figure lb) decreased slightly in both groups but returned to preinduction levels by the sixth minute. This decrease was quantitatively greater in Group $A$, but the differ. ence was not significant.

Minute volume (which was derived from tidal volume and respiratory rate) (Figure 1c) decreased following induction of anaesthesia in Group $A$ and reached a minimum value at two 331 minutes, thereafter gradually increasing to levels 
TABLE I

Summary of Patients With Mean Values \pm 1 S.D.

\begin{tabular}{ccccc}
\hline Group & Number & $\begin{array}{c}\text { Age } \\
\text { (yrs) }\end{array}$ & $\begin{array}{c}\text { Weight } \\
\text { (Kg) }\end{array}$ & $\begin{array}{c}\text { Anaesthetic } \\
\text { time } \\
\text { (min) }\end{array}$ \\
\hline A Alfathesin fentanyl & 24 & $23.0 \pm 3.5$ & $58.6 \pm 6.2$ & $8.4 \pm 3.3$ \\
B Alfathesin only & $29 *$ & $22.0 \pm 2.7$ & $57.1 \pm 6.3$ & $9.7 \pm 2.8$ \\
& & N.S. & N.S. & N.S. \\
\hline
\end{tabular}

*Two patients were excluded from this analysis (see text).

TABLE II

Doses of Drugs EMPloyed

\begin{tabular}{|c|c|c|c|c|c|c|}
\hline & Group & $\begin{array}{l}\text { Mean } \\
\text { induction } \\
\text { dose }\end{array}$ & $\begin{array}{l}\text { Mean } \\
\text { infusion } \\
\text { dose }\end{array}$ & $\begin{array}{c}\text { Patients } \\
\text { requiring } \\
\text { supplementary } \\
\text { doses }\end{array}$ & $\begin{array}{c}\text { Mean } \\
\text { supplementary } \\
\text { dose }\end{array}$ & $\begin{array}{l}\text { Mean } \\
\text { total } \\
\text { dose }\end{array}$ \\
\hline A & $\begin{array}{l}\text { Alfathesin, } \\
\text { fentanyl }\end{array}$ & $75 \mu \mathrm{l} / \mathrm{kg}$ & $2.8 \mu \mathrm{l} / \mathrm{kg} / \mathrm{min}$ & $8(33 \%)$ & $16 \mu \mathrm{l} / \mathrm{kg}$ & $104 \mu \mathrm{l} / \mathrm{kg}$ \\
\hline B & $\begin{array}{l}\text { Alfathesin } \\
\text { only }\end{array}$ & $75 \mu \mathrm{l} / \mathrm{kg}$ & $2.7 \mu \mathrm{l} / \mathrm{kg} / \mathrm{min}$ & $14(52 \%)$ & $15 \mu 1 / \mathrm{kg}$ & $110 \mu \mathrm{l} / \mathrm{kg}$ \\
\hline
\end{tabular}

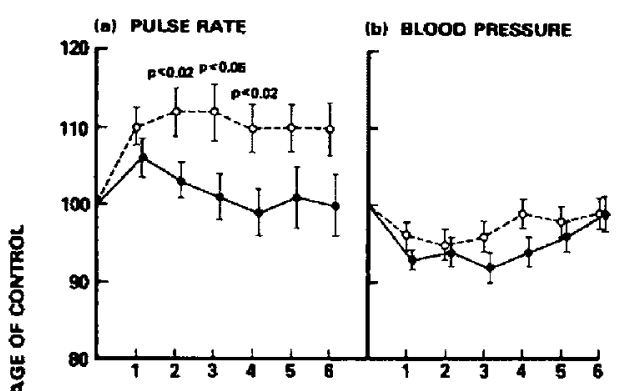

(c) MiNUTE VOLUME (d) RESPIRATORY RATE

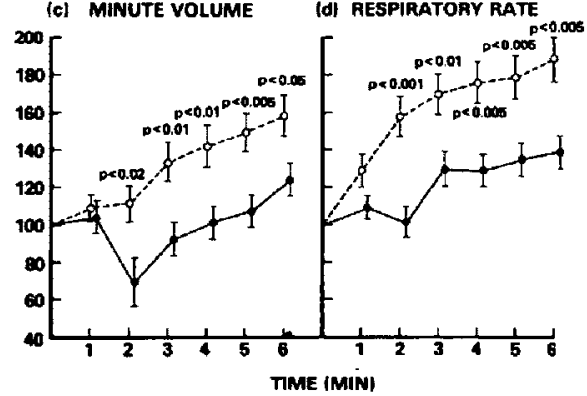

Figure I The change in four parameters during the first six minutes after induction of anaesthesia shown as mean values $\pm 1 \mathrm{~S}$. E. O - . - O represents alfathesin only (Group B). represents alfathesin + fentanyl (Group A). Significant differences are indicated. slightly above the pre-induction values. Conversely, patients in Group B showed an immediate and increasing rise in minute volume. This difference was statistically significant from the second to sixth minutes.

Respiratory rate (Figure 1d). Group A patients showed little change in respiratory rate during the first two minutes, followed by a slight increase in rate to between 130 and 140 per cent of the pre-induction values. In marked contrast, Group B patients showed an initial and increasing elevation of respiratory rate. This difference was highly significant from the second to the sixth minutes.

Recovery times (Table III). Group B (alfathesin alone) patients showed a significantly shorter $(P<0.02)$ time to "open eyes" (3.7 minutes compared to 5.6 minutes in Group A). These patients also reported a more rapid "subjective" recovery time, but this was not statistically significant. "Orientation" and "sit up" times were similar in both groups.

Side effects (Table IV) occurred with similar incidence in both groups. There was a lower incidence of per-operative movements in those patients receiving fentanyl, but a higher incidence of transient apnoea. The incidence of clinically undesirable side effects such as cough and laryngospasm was higher in those patients receiving alfathesin alone. Indeed, two patients in this 
DUNN, et al.: FENTANYL AND ALFATHESIN

TABLE $I 11$

Recovery Times as Mean Values \pm 1 S.D.

\begin{tabular}{|c|c|c|c|c|c|}
\hline & & Open eyes (min) & Orientation (min) & Sit up $(\min )$ & Subjective (hr) \\
\hline A & $\begin{array}{l}\text { Alfathesin, } \\
\text { fentanyl }\end{array}$ & $5.6 \pm 3.3$ & $8.0 \pm 3.0$ & $9.7 \pm 3.0$ & $3.25 \pm 5.14$ \\
\hline B & $\begin{array}{l}\text { Alfathesin } \\
\text { only }\end{array}$ & $\begin{array}{c}3.7 \pm 1.9 \\
P<0.02\end{array}$ & $\begin{array}{c}7.9 \pm 3.7 \\
\text { N.S. }\end{array}$ & $\begin{array}{c}10.2 \pm 4.2 \\
\text { N.S. }\end{array}$ & $\begin{array}{c}1.82 \pm 1.5 \\
\text { N.S. }\end{array}$ \\
\hline
\end{tabular}

TABLE IV

Incidence of Per-operative Side Effects

\begin{tabular}{lcc}
\hline \hline Side effects & $\begin{array}{c}\text { Alfathesin, } \\
\text { fentanyl } \\
(\mathrm{n}=24)\end{array}$ & $\begin{array}{c}\text { Alfathesin } \\
\text { only } \\
(\mathrm{n}=29)\end{array}$ \\
\hline Apnoea & 8 & 2 \\
Cough & 1 & $3^{*}$ \\
Hiccup & 3 & 2 \\
Laryngospasm & 1 & $2 *$ \\
Movements & 8 & 16 \\
Secretions & 1 & 1 \\
Skin rash & 1 & 1 \\
Vomiting & 0 & 1 \\
Total patients $\dagger$ & $16(67 \%)$ & $18(62 \%)$ \\
(Less movements) & $11(46 \%)$ & $8(28 \%)$ \\
\hline
\end{tabular}

*One severe (see text).

†Some patients exhibited multiple side effects.

TABLE $\checkmark$

InCIDENCE of Post-operative Side Effects

\begin{tabular}{llllll}
\hline & \multicolumn{2}{c}{$\begin{array}{c}\text { Alfathesin, } \\
\text { fentanyl }\end{array}$} & & \multicolumn{2}{c}{$\begin{array}{c}\text { Alfathesin } \\
\text { only }\end{array}$} \\
\cline { 2 - 3 } \cline { 5 - 6 } Side effects & $1 \mathrm{hr}$ & $1-5 \mathrm{hr}$ & & $1 \mathrm{hr}$ & $1-5 \mathrm{hr}$ \\
\hline Abdominal cramps & 2 & 0 & & 2 & 0 \\
Cough & 0 & 0 & & 3 & 0 \\
Crying & 0 & 0 & & 2 & 0 \\
Dizziness & 1 & 1 & & 1 & 0 \\
Headache & 1 & 0 & & 0 & 2 \\
Nausea & 2 & 3 & & 4 & 1 \\
Vomiting & 2 & 3 & & 3 & 1 \\
Total patients & $8(33 \%)$ & $7(29 \%)$ & $9(31 \%)$ & $4(14 \%)$ \\
\hline
\end{tabular}

group developed side effects which necessitated exclusion of these cases from the study and subsequent statistical analysis of physiological variables and recovery time. One patient developed severe laryngospasm requiring administration of succinylcholine and tracheal intubation and the second patient developed a marked cough which ceased upon the administration of halothane. The overall incidence of side effects was 67 per cent in those patients receiving fentanyl, and 62 per cent in those patients recejving alfathesin alone.

Postoperative side effects (Table V) occurred with a similar frequency in both the groups during the first hour following anaesthesia. Between the first and fifth hours post-operatively, patients who had received fentanyl showed a higher inci- 
dence of side effects (29 per cent versus 14 per cent) which reflected a greater susceptibility to nausea and vomiting in these patients.

\section{Discussion}

The objective of this study was to assess the influence of a small dose of fentanyl on the cardiorespiratory effects and clinical efficacy of an alfathesin infusion technique. Previous studies have utilized infusion rates regulated according to patient response. ${ }^{8.9}$ In this study, similar induction and infusion doses of alfathesin were used in both groups of patients, to make a meaningful assessment of the effects of fentanyl. The use of standardized supplementary doses, administered only in response to patient movement, allowed satisfactory anaesthesia to be maintained without compromising the objectivity of the study.

The high incidence of movement in both groups ( 52 per cent of patients in the alfathesin group and 33 per cent in the alfathesin fentanyl group) indicates that a higher infusion rate would be required to make this technique more acceptable clinically.

The total dose of alfathesin used in the alfathesin group was approximately five per cent higher than in the alfathesin-fentanyl group. This was due to two factors; first, as mentioned above, there were more movements during operation in the alfathesin group, resulting in a larger number of supplementary doses in this group and, secondly, the anaesthetic time in this group was slightly longer, resulting in a higher total infusion dose. Overall, however, the difference in total alfathesin doses employed was not statistically significant.

The difference in cardiorespiratory effects between the two groups was surprising, since the fentanyl dose used ( $1 \mu \mathrm{g} / \mathrm{kg}$ ) was small. Although there was a tendency for the blood pressure to be slightly lower in the group receiving fentanyl, this difference was not statistically significant. There was a marked and statistically significant difference in the pulse rates between the two groups from the second to sixth minutes, which was approximately 10 per cent higher in patients whodid not receive fentanyl. This was likely due to better anaigesia in the patients receiving fentanyl and to the vagomimetic effects of the drug itself. ${ }^{10}$ Similarly, there was a marked and statistically significant difference in both minute volume and respiratory rate between the two groups, from the second to sixth minutes. Patients receiving fen- tanyl showed respiratory rates and minute volumes approximately 30 to 40 per cent lower than those receiving alfathesin alone. This was probably due to the analgesic and respiratory depres. sant properties of fentanyl. " In both groups there was a tendency towards hyperventilation and tachypnoea as anaesthesia progressed, which probably reflects the respiratory stimulant properties of alfathesin and the light levels of anaesthesia obtained in both groups.

Immediate recovery, as reflected by time to "open eyes", was longer in those patients who had received fentanyl, but there was no difference in "orientation" or "sit up" times between the two groups. Recovery in both groups was rapid and the difference was not significant clinically. The addition of fentanyl to the infusion technique resulted in a lower incidence of movements. There was a higher incidence of transient apnoea which was not thought to be significant clinically. Perhaps the most clinically significant difference was the fact that two patients receiving alfathesin only developed side effects during operation which necessitated abandoning the infusion protocol. This was probably due to the light level of anaesthesia and lack of analgesia in this group.

In conclusion, the addition of fentanyl to an alfathesin infusion technique produced more satisfactory anaesthesia with fewer undesirable side effects and a more stable cardiorespiratory response. The improvement in clinical anaesthesia resulted in only marginally increased recovery times. Fentanyl would therefore seem to be a useful addition to an alfathesin infusion technique when used in unpremedicated patients presenting for outpatient anaesthesia.

\section{SUMMARY}

The effects of fentanyl $(1 \mu \mathrm{g} / \mathrm{kg})$ supplementing an alfathesin infusion technique were assessed in a double blind study in 53 healthy unpremedicated female patients undergoing therapeutic abortion as outpatients. The addition of fentanyl reduced the tachycardia, tachypnoea and hyperventilation seen in those patients receiving alfathesin alone, without unduly prolonging recovery time. Two patients receiving alfathesin alone developed marked coughing or laryngospasm.

Fentanyl would seem to be a desirable addition to an alfathesin infusion technique in unpremedicated patients presenting for outpatient anaesthesia. 


\section{RÉSUMÉ}

Les effets de l'association de fentanyl (1 $\mathrm{mg} / \mathrm{kg}$ ) à l'alfathesin en perfusion continue ont été étudiés chez 53 patientes en bonne santé, non prémédiquées et anesthésiées pour avortement thérapeutique. L'administration de fentanyl a réduit lincidence de la tachycardie, de la tachypnée et de l'hyperventilation constatée chez celles qui ne recevaient que l'alfathesin, sans en prolonger le réveil de façon marquée. De plus, une toux opiniâtre et un larygospaseme sont survenus chez deux patientes qui n'avaient pas reçı de fentanyl. Les auteurs croyent qu'il est désirable d'injecter du fentanyl pour la chirurgie ambulatoire de patientes non prémédiquées et anesthésiées par une perfusion continue d'alfathesin.

\section{ACKNOWLEDGEMENTS}

The authors wish to thank their colleagues in the Departments of Anaesthesia and Gynaecology, and the Operating Room staff at McMaster University Medical Centre for their co-operation. Special thanks is due to Sheila Seaman for her assistance in the manuscript preparation.

The study was supported by a grant-in-aid from Glaxo Laboratories, who also provided supplies of alfathesin.

\section{REFERENCES}

1. SWERDLow, M. Althesin - a new intravenous anaesthetic. Canad. Anaesth. Soc. J. 20: 186 (1973).
2. Savege, T.M., Foley, E.l., Coultas, R.J., Walton, B., Strunin, L., Simpson, B.R., \& ScotT, D.F. CT 1341: some effects in man. Cardiorespiratory, electroencephalographic and biochemical changes. Brit. J. Anaesth. 26: 402 (1971).

3. Tammisto, T., Takki, S., Tigerstedt, I., \& KaUSTE, A. A comparison of althesin and thiopentone in induction of anaesthesia. Brit. J. Anaesth. 45: 100 (1973).

4. Broadley, J.N. \& Taylor, P.A. An assessment of althesin for the induction of anaesthesia in cardiac surgical patients - a comparison with thiopentone. Brit. J. Anaesth. 46: 687 (1974).

5. arora, M.V.. Carson, I.W.. \& Dundee, J.W. Alterations in response to somatic pain associated with anaesthesia. XXI Althesin (CT 1341). Brit. J. Anaesth. 44:590 (1972).

6. DU Callar, J. The effects in man of infusions of Althesin with particular regard to the cardiovascular system. Postgrad. Med. J. Suppl. (2) 48: 72 (1972).

7. Dunn, G.L., Houlton, P.J., Morison, D.H. \& Rajagopalan, R. A comparative assessment of alfathesin for use in outpatient anaesthesia. Canad. Anaesth. Soc. J. 25: 125(1978).

8. DeCHÊNE, J.P. Alfathesin by continuous infusion supplemented with intermittent pentazocine. Canad. Anaesth. Soc. J. 24: 702 (1977).

9. Savege, T.M., Ramsay, M.A.E., Curran, J.P.J., Cotter, J., Walling, P.T., \& Simpson, B.R Intravenous anaesthesia by infusion. Anaesthesia 30: 757 (1975).

10. FREYe, E. Cardiovascular effects of high dosages of fentanyl. meperdine, and naloxone in dogs. Anesth. \& Analg. 53: 40 (1974).

11. Goodman, L. \& Gilman, A. (ed.). The Pharmacological Basis of Therapeutics, 5th ed. New York: Macmillan (1975). 